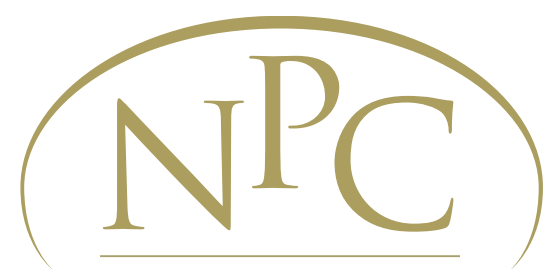

NATIONAL POVERTY

CENTER

National Poverty Center Working Paper Series

\#13-01

January 2013

\title{
Pensions for Singles and Couples
}

\author{
Bruce Bradbury, University of New South Wales
}

This paper is available online at the National Poverty Center Working Paper Series index at: http://www.npc.umich.edu/publications/working_papers/

Any opinions, findings, conclusions, or recommendations expressed in this material are those of the author(s) and do not necessarily reflect the view of the National Poverty Center or any sponsoring agency. 


\title{
Pensions for singles and couples
}

\author{
Bruce Bradbury \\ Social Policy Research Centre \\ University of New South Wales \\ Sydney, Australia \\ b.bradbury@unsw.edu.au
}

\begin{abstract}
Retirement policies often seek to set minimum pensions at levels that enable single and married pensioners to have the same standard of living. The existing literature on consumer equivalence scales provides little assistance in reaching this policy objective, as the estimated scales are both imprecise and reliant upon strong and opaque assumptions. This paper proposes an alternative modelling strategy which has low data requirements and involves the use of detailed, but transparent, assumptions about the extent of joint consumption of particular commodities. These assumptions are embedded in an economic model of household consumption and combined with household expenditure data to calculate consumer equivalence scales.

It is estimated that Australian couples of Age Pension age who own their own home need expenditures between 1.32 and 1.60 times that of single person households in order to have the same effective consumption level. These scales are lower than those used in the pension system at the time the research was undertaken.
\end{abstract}

JEL: I38, D13, J14

Keywords: Consumer equivalence scales, Pensions

\section{Notes}

This research was supported by the Australian Government Department of Families, Housing, Community Services and Indigenous Affairs (FaHCSIA) and by the Australian Research Council (DP0878643). The opinions, comments and/or analysis expressed in this document are those of the author and do not necessarily represent the views of the Minister for Families, Housing, Community Services and Indigenous Affairs or FaHCSIA, and cannot be taken in any way as expressions of Government policy. Research assistance from Silvia Mendolia and comments from Peter Saunders are gratefully acknowledged. 


\section{Introduction}

Retirement policies often seek to set minimum pensions at levels that enable single and married pensioners to have the same standard of living. Information about relative needs is also a central requirement for poverty and inequality measurement. Seemingly, data on household consumption patterns should be able to inform these applications. However, consumption research typically plays little part in the setting of pension relativities, and has a very limited input into poverty and inequality measurement. Research-based relativities with useful levels of precision require both very strong and opaque assumptions and/or have very high data requirements.

This paper introduces a modelling framework that can be used when deriving such 'consumer equivalence scales'. It is set in the context of consumer demand theory and uses data on consumer expenditure patterns, but also draws upon systematically assembled assumptions about the joint consumption of commodities in the household. These assumptions are akin, but weaker, than those used in the normative 'budget standards' literature. The key strengths of the method are that data requirements are low and the assumptions used are quite transparent. The key weakness is that assumptions (or external evidence on the technology of home consumption) are required. Nonetheless, the clear link between assumptions and conclusions used in this framework means that it can be used to provide a key input into normative pension policy (and possibly also for related distributional research). This framework is applied to estimate the relative needs of singles and couples of Age Pension age in Australia.

The Australian Age Pension is non-contributory pension paid to around three-quarters of the population over retirement age (high-income or wealth people are excluded). Prior to September 2009, the Australian Age Pension had a base rate of payment for a couple that was 1.64 times the single rate of pension. ${ }^{1}$ For several years, Australian seniors groups had been campaigning to seek increases in the relative payments for single

1 This is for home-owners and includes utility, telephone and pharmaceutical allowances. As a comparison, the couple/single ratio in the UK Basic State Pension is 1.60 when only one member of the couple has qualifying National Insurance contributions (www.direct.gov.uk accessed 5 August 2010). 
pensioners. ${ }^{2}$ Moreover, the couple/single ratio was higher than many equivalence scales in common use in poverty research. In their 1988 survey Buhmann et al found that scales based on subjective evaluations of well-being had very high economies of scale (median couple/single ratio of 1.18), while scales based on expenditure patterns or derived from official poverty lines had economies of scale averaging 1.32 and 1.42 respectively. (Though it should be noted that these summary statistics are averaged across all family sizes, and not specifically developed for the comparison of singles and couples). Only scales arbitrarily created by statistical agencies or researchers had similar scale economies to the Australian pension scale relativity.

These different approaches are considered in more detail in the next section of the paper. The method used here includes elements of both the consumption theory and the normative 'budget standards' approach. The 'Barten' model used in this paper is introduced in Section 3. The calculation methods used in this paper do not require the estimation of a full consumer demand system, but instead are based on price index-like weighted averages of budget shares. The implications of using the Barten simplifications are discussed with reference to a more general household consumption model which is outlined in the Appendix. Section 4 then provides estimates of the relative needs of Australian older couples and singles who own their own homes. A number of extensions to these estimates are presented in Section 5. These include estimates of the impact of age on the relativity between singles and couples, the relative needs of single and couple private renters, and the relative needs of two-person, non-couple households. Section 6 concludes.

\section{Equivalence scale estimation}

There is a longstanding debate in the economics literature on whether the consumer equivalence scale is a meaningful concept. If people can choose their family size, then it makes little sense to assume that they are worse off when they make a choice to have a larger (or smaller) family. Why should we be interested in estimating the costs but not

2 Yates (2009, p1). See also Barber et al (1994) and Patterson and Wolffs (1995) who presented anecdotal and focus group evidence about the perceived drop in living standards experienced by pensioners after the death of their partner.

3 See for example, Pollak and Wales (1979) and Blundell and Lewbel (1991). The latter conclude that to use equivalence scales derived from demand data for welfare comparisons is inherently dishonest or at 
the benefits associated with household structure, and why should income transfer programs take account of these costs?

One reason is that researchers and policy-makers are often interested in the living standards of people who have little choice over their living arrangements. This is relevant when considering the living standards of children, who did not choose to be brought into the world nor the number of siblings they have. It might also be considered relevant to the situation of the majority of older singles, because they have arrived in this situation via widowhood.

More generally, we might wish to apply social norms that are not automatically derived from individual behaviour. ${ }^{4}$ These might include the right of individuals to choose their demographic status without incurring economic penalties. For example, a goal of pension policy for the elderly might be to permit both singles and couples to live in their preferred household composition while attaining the same material standard of living. Similarly, social goals of poverty alleviation are usually defined within the narrower context of commodity-based consumption - partly because economic and social policy is not very effective in altering demographic choices or providing the benefits (such as companionship) that flow directly from household composition. Hence anti-poverty policy seeks to take consumer equivalence scales into account in setting rates of payment (Nelson, 1993; Bradbury, 1996). This focus on commodity consumption is also a justification for ignoring the leisure and home production costs and benefits of various domestic arrangements.

Within this narrower framework of consumption-based welfare, there is a large and longstanding body of research seeking to measure the relative needs of families of different compositions (Buhmann et al, 1998). The methods used can be grouped into three broad categories based on their most important identifying assumptions.

least uninformative' (p. 66). This present paper argues that, contrariwise, the types of scale estimated here are very informative for the narrower questions of relevance to pension policy.

4 That is, social welfare functions may have a more restricted set of arguments than individual welfare functions, excluding preferences over demographic circumstances. 


\section{Well-being indicator based}

Subjective measures of economic well-being or hardship can be compared with income levels to ascertain the income level needed to maintain constant well-being across different household types (eg Kapteyn and Wansbeek, 1985). This controls for the different income levels of people in different household types.

The validity of this approach rests on the assumption that responses to these questions accurately reflect the concept of well-being that is of interest to researchers. This might not be the case, for example, if subjective well-being is influenced by expectations, particularly if these in turn are influenced by the living standards of people in other households of the same type as the respondent. If this is the case, responses might be biased so that demographic groups which are really at different standards of living actually report very similar standards of subjective well-being (Bradbury, 1989). More practically, these indicators are typically only weakly associated with income and family composition and thus require very large samples for accurate estimation.

\section{Budget standards based}

Budget standards involve researchers assembling a list of consumption goods needed to attain some given living standard, such as 'modest but adequate', (eg Saunders et al, 1998). These are then costed for different family types. Though this method produces precise estimates, it can be difficult to justify the assumptions needed to build the list of goods and the weights to be placed on each category of expenditure.

\section{Consumption theory based}

Several different approaches have been developed using data on household expenditure patterns, employing a variety of identifying assumptions. These include: that the food share is an indicator of household well-being (Engel, 1857); that family composition has only an income effect on some non-shared goods (Rothbarth, 1943); that composition has only a price effect (Barten, 1964); and that the equivalence scale is constant at all income levels (Lewbel, 1989, Blackorby and Donaldson, 1991).

Gorman summarised the price-like impact of household composition using the words of his schoolmaster: 'When you have a wife and a baby, a penny bun costs threepence' (Gorman 1976, p215). At the same time, when extra members enter the household there 
is only a small increase in the effective price of jointly-consumed goods like heating, which are thus relatively cheaper per person. This equivalence between household size and price effects was first used by Barten (1964) to estimate price responses from data where all subjects faced the same prices. Subsequent research using this model has generally sought to do the opposite - use information on behavioural responses to price changes, together with information on consumption patterns in households of different sizes, to estimate the degree of joint consumption (eg Muellbauer, 1977, Nelson, 1988). This 'Barten model' is used as the modelling framework in this paper, with an identification approach that is closer in spirit to Barten's original approach than that of the more recent research.

Even aside from any issues of empirical identification, however, the limitations associated with the simple structure of the Barten model are well recognised. In particular, the model does not account of differences in consumption preferences between household members and the within-household distribution of income. As Gorman (1976) also noted, threepence worth of penny buns fills three stomaches, but threepence worth of beer only satisfies the beer drinkers in the household. Nonetheless, it has been argued that this model might serve as a reasonable approximation for households of multiple adults (Nelson, 1988).

\section{The Barten Equivalence Scale Model}

The Barten consumption model can be considered as a special case of a more general model of household welfare and consumption technology. Consider a household consisting of two people. We assume that when either person $j$ lives alone and has income $y$, they choose their consumption of market commodities $q_{i j}$ so as to maximise a conventional utility function $u_{j}=U_{j}\left(q_{1 j}, q_{2 j}, \ldots, q_{I j}\right)$ subject to their budget constraint $\sum_{\mathrm{i}} p_{i} q_{i j} \leq y$.

When they share a household, household consumption is chosen so as to maximise a separable function of the welfare of each household member, subject to a household budget constraint. That is, 


$$
\begin{aligned}
& \max U\left(u_{1}, u_{2}\right) \\
& \text { subject to } \sum_{\mathrm{i}} p_{i} Q_{i}\left(q_{i 1}, q_{i 2}\right) \leq y
\end{aligned}
$$

The function $Q_{i}\left(q_{i 1}, q_{i 2}\right)$ represents the household purchase requirement for commodity $i$ (Lau, 1985). For goods that cannot be shared, it is simply the sum of the personal consumption amounts $q_{i j}$. However, for goods which have some degree of joint consumption or sharing, the purchase requirement will be less than this. The properties of this general household purchase function are discussed further in the Appendix.

The household welfare function $U($.$) can be interpreted in several ways. Most simply, it$ might be considered to represent the preferences of a 'caring' but 'non-paternalistic' household head who controls household consumption. The individual welfare functions might then be the head's views on the needs of the other household member. Becker (1981) shows that this interpretation can hold even when the other individuals have some control over their own consumption.

Alternately, if $\mathrm{U}($.$) is additive, then the first order solution to this household decision$ problem is identical to the outcome of a Pareto efficient allocation of consumption between the household members (Panzar and Willig, 1976). The function U(.) can then be interpreted as a summary of the relative bargaining strengths of the individuals in the household. 'Bargaining strength' in this context should be interpreted broadly, including the impact of altruistic feelings for the welfare of other household members. In general, $\mathrm{U}($.$) might also be a function of other variables influencing bargaining within the$ household such as wage rates, private incomes, and social norms of within-household distribution. By definition, preferences over household composition itself do not enter $\mathrm{U}($.$) .$

Incorporation of bargaining factors would make the present model similar to that in the 'collective consumption' literature (Chiappori, 1988, 1992, Browning et al, 1994 and Apps and Rees, 1997). One difference is that most of the collective consumption models are unable to fully recover the household income-sharing rule because they do not assume that individuals' preferences are stable across household types (Browning, 
Chiappori and Lewbel, 2006 is an exception). Here, as in all the equivalence-scale literature, this is a necessary identifying assumption.

To arrive at the Barten model, we introduce two additional simplifying assumptions; there is equal sharing of resources within the household, and the two individuals have the same preferences for commodities. That is, $U($.$) is assumed symmetric and U_{1}($.$) has the$ same functional form as $U_{2}($.$) . With these assumptions the purchase function for$ commodity $i$ is simply $Q_{i}=r_{i} q_{i 1}=r_{i} q_{i 2}$ (see the Appendix). That is, $q_{i 1}=q_{i 2} \forall i$ and the household needs to purchase $r_{i}$ times more of the commodity than each person consumes. If good $i$ is not shared, $r_{i}=2$ and the household has to purchase twice the consumption of each person, while if it is a pure public good within the household then $r_{i}=1$ with each unit of purchase providing a unit of consumption for each person.

In these circumstances, the household faces a purchase decision problem of maximising one of the individual welfare functions $U_{j}\left(q_{1 j}, q_{2 j}, \ldots, q_{l j}\right)$ (they are identical) subject to a household budget constraint $\sum_{\mathrm{i}} p_{i} r_{i} q_{i j} \leq y \quad$ (where $j=$ either 1 or 2 ). Since the symmetry assumptions imply equal sharing of income within the household, we can write the budget constraint in terms of the income received by each person as $\sum_{\mathrm{i}}\left(p_{i} r_{i} / 2\right) q_{i j} \leq y / 2$, which it makes it clear that the decision problem is the same as that for the one-person household, except that they are now allocating half the household income and are facing prices that are $r_{i} / 2$ times market prices. The interpretation of the purchase function parameters $r_{i}$, and potential strategies for assigning reasonably bounds for them, are discussed further below. Once known, however, standard price index theory can be used to derive household equivalence scales.

Denoting the budget share of commodity group $i$ by $w_{i}=q_{i} p_{i} / y$, a representative person living alone and with income $y^{0}$ consumes $q_{i}^{0}=w_{i}^{0} y^{0} / p_{i}$ of each commodity and reaches welfare level $u^{0}$. In the couple household, the Barten assumptions imply that the husband and wife consume the same amount of each commodity and income is equally shared between them. When the couple household purchases a quantity $Q_{i}$, of 
each commodity, each person consumes $q_{i j}^{1}=Q_{i} / r_{i}$ and reaches a welfare level of $u^{1}$. Personal consumption of each commodity can then be expressed in terms of household budget shares and income as $q_{i j}^{1}=w_{i}^{1} y^{1} / r_{i} p_{i}$.

A Laspeyres equivalence scale (corresponding to a Laspeyres price index) for the cost of a couple relative to a single person can then be defined as $m_{L}=\sum_{i} q_{i}^{0} p_{i} r_{i} / \sum_{i} q_{i}^{0} p_{i}$. The denominator is the expenditure required by a single person to consume the vector $q^{0}$. The numerator is the expenditure required by the couple household so that each individual can consume the same vector $q^{0}$. Using the relationships shown in the paragraph above, this simplifies to $m_{L}=\sum_{i} w_{i}^{0} r_{i}$, the average relative purchase requirement for each commodity, weighted by the single-person budget shares.

Now $q^{0}$ is the bundle of goods chosen by the single-person household. It will not necessarily be the welfare-maximising quantity for the people in the couple households and it is possible that couples could achieve the same welfare level at a lower total expenditure by substituting towards goods which are shared and are thus effectively cheaper. This means that the true equivalence scale at welfare level $u^{0}$, must be less than $m_{L}$ (or equal if there is no substitution).

Similarly, a Paasche equivalence scale can be calculated using couple-consumption patterns as weights. This represents the cost of consuming the consumption bundle of the individuals when living as couples, and is defined as $m_{P}=\sum_{i} q_{i}^{1} r_{i} p_{i} / \sum_{i} q_{i}^{1} p_{i}=1 / \sum_{i} w_{i}^{1} \frac{1}{r_{i}}$, i.e. the harmonic mean of the relative purchase requirements, weighted by couple-income shares. Following similar reasoning to above, this scale will be a lower bound for the true equivalence scale calculated at welfare level $u^{15} \cdot$

5 It might also be noted that an alternative, apparently plausible, method for calculating an equivalence scale might be to calculate the arithmetic average of the commodity-specific scales with the couple budget shares as weights. Such a 'naive' scale leads to a higher estimate of the equivalence scale than either the Paasche or Laspeyres scales. 
In the main empirical analysis below, these scales are calculated at the mean budget shares of single and couple households. Plutocratic shares are used for the base results (total expenditure on good $i$ divided by total expenditure). The geometric mean of the Laspeyres and Paasche scales is also calculated (the 'Fisher ideal' scale).

When the Laspeyres and Paasche scales are calculated at the same welfare level, the bounds above can be combined to form upper and lower bounds for the true scale at that welfare level (and the Fisher scale is a reasonable compromise). However, unless singles and couples are on average equally well off (or preferences are homothetic) we would not expect their observed average budget shares to reflect the consumption patterns that would occur if they were at the same welfare level - and so combining the two scales is problematic.

To take account of this, we also present some scales where singles and couples are at approximately the same welfare level. This is calculated by starting from the budget share allocation of singles whose household income ${ }^{6}$ is in the middle quintile group of the income distribution of singles, calculating the Laspeyres scale, multiplying this by the average income of singles in the middle quintile to obtain the income required in the couple household to be at the same welfare level, then calculating the Paasche scale for couples at this income level (interpolated from quintile-specific scale calculations). As it turns out, there is not much variation in the Laspeyres and Paasche scales across income levels and so the Fisher scale calculated from this procedure is very close to the simple average of the Laspeyres and Paasche scales calculated at average budget shares (see Table 2 and Section 5.1 for more discussion).

\subsection{Implications of the Barten simplifications}

More generally however, the Barten model does rest on a very restrictive model of household consumption allocations. Aged couples do not consist of identical twins, and we cannot assume that resources are shared equally between them. Are these simplifying

6 These calculations are made by grouping by income rather than expenditure quintiles to avoid the endogeneity bias due to measurement error and transitory variations in expenditures. For example, expenditure on capital goods (such as whitegoods or car purchase which are averaged over a 12 month period) might lead to household being in the top quintile of expenditure even though their consumption level is lower. Because capital goods tend to be public, this distorts the pattern of equivalence scales across groups. 
assumptions likely to have much impact on the equivalence scales that are relevant to pension policy?

It is clear that the within-household sharing of income must be relevant to the true person-specific equivalence scale. If one member receives the bulk of household resources then they will need only a low two-person household income for them to have the same living standard they would have if single. The opposite applies to the other person. On average, these two effects cancel out; the extra income in the couple household for one person is equal to the reduced income for the other.

Even if unequal sharing of resources could be identified empirically, it is unlikely that this would be generally applied to pension policy. At face value, unequal within-household sharing suggests that categories of people who receive a greater share of resources in couple families should also receive a higher pension when single. This might be ethically justifiable if the within-household inequality arose from differences in socially-approved needs (eg one person has high medical expenses or nutritional needs), but would not be justifiable if it arose from inequality of power within the household. Given the difficulty in separating these determinants, it would seem reasonable to initially focus on an estimate of the average couple/single relativity.

As well, however, if the personal welfare function is concave, then an unequal distribution of resources within the household will mean a lower average welfare level than if the same resources were equally allocated (assuming identical cardinal welfare functions). Even if resources within retired couples are distributed equally on average (as evidence seems to suggest, see Bradbury, 1997), there is likely to be variation around this average. The results here do not take account of this within-household inequality and hence will tend to underestimate the average relative needs of couple households. But this is only one example of the more general phenomena of income and need heterogeneity that is not addressed in poverty and inequality measurement. The results here are thus best interpreted as describing the relative needs of singles and couples that could be achieved if resources were equally shared within the couple.

The Barten model also assumes that each member of the household has the same consumption preferences. However, in practice these are likely to diverge significantly, 
particularly for narrowly defined commodity groups. In this situation the effective (or 'shadow') price of the good in the two-person household can vary depending upon the consumption of the other member. In general, for goods that are partly public, a higher level of consumption by the second household member implies a lower shadow price for the first member (see appendix). This effect is strongest for pure public goods where the household purchase requirements are simply the maximum of personal consumption levels. A person consuming less than the maximum can thus increase their consumption without the household needing to purchase more of the good - implying a shadow price of zero for this person but a market price for the maximum consumer. At the other extreme, the shadow price is always equal to the market price (and hence not sensitive to unequal consumption) for goods that are fully private. Conveniently, these are also the goods where unequal consumption is most prevalent, for example, men's and women's clothing.

Nonetheless, for goods which are public or semi-public within the household, prices will vary according to the consumption of each member. On average, these variations will tend to offset each other. Holding constant the overall between-person distribution of resources, if a person is the primary consumer of commodity $\mathrm{A}$, they will be less likely to be the primary consumer of commodity B. These offsetting effects mean that the impact on the average equivalence scale that they face will be small (though non-linearities mean that there may be some differences). This is confirmed in Bradbury (1997) where a model of the more general form described in the appendix is estimated, and equivalence scales are derived that are very close to those derived when using the Barten assumptions.

\subsection{Implications of home production}

Bradbury (1997) also tests whether the actual consumption patterns of households are consistent with this consumption framework. The main divergence is found in prepared food consumption; couples spend more on food than the consumption patterns of singles and the sharing assumptions would suggest. These changes probably arise from the incentives associated with home production. Because the time required to cook for two is not much more than the time required to cook for one, there are strong incentives for couples to engage in more home food preparation. 
It is not clear, however, that pension policy should take these time costs into account. These patterns of consumption imply that pensioners do value their time - they spend less time on activities that yield less output. Nonetheless, they still have much of what, by average community standards, might be considered 'free' time. Current discourse on public pension policy does not include discussion of compensation to single pensioners for their lost efficiency of home production time. These results in this paper follow this convention of not considering these time costs. ${ }^{7}$ Again, this points to the necessarily central role of normative assumptions in the estimation of policy-relevant consumer equivalence scales.

\section{Estimates of the relative needs of older single person and couple households}

The estimation of relative needs in this model requires information on the expenditure shares of singles and couples on different commodity groups, and the magnitudes of the relative purchase requirement parameters, $r_{i}$. The budget shares of total current expenditure are estimated from the Australian Bureau of Statistics Household Expenditure Surveys of 1988-89, 1993-94, 1998-99 and 2003-04. Attention is confined to households with one adult or with two adults of opposite sex, all of whom are AgePension age or older (65 for men, 62 for women in 2003-04, 60 for women in other years). To control for wealth effects attention is restricted to home-owning households (with or without a mortgage). This includes four-fifths of retired households. Costs for renters are examined separately in Section 5.

Rather than attempting to estimate the relative purchase requirements, $r$, using their affinity with price effects, they are treated here as assumed technological features of household consumption, albeit influenced by social norms of consumption. Some goods are close enough to entirely private (eg men's and women's clothing) to make an assumption of pure private $(r=2)$ reasonable. Most goods, however, have some features that imply that the household will need to purchase less than twice the amount that is

See Bittman (1991) for a discussion of the gender differences in home production in older households and Bradbury (1998) for a model of the costs of children incorporating home production. If economies of home production time were included as relative benefit for couples, this would reinforce the conclusion of this paper that couples are better off under the existing pension relativities. 
consumed by each person. Can we conceptualise the technology of consumption in a way that helps us formulate reasonable assumptions about this degree of sharing?

One approach is to conceptualise these semi-public goods as part pure-private and part pure-public (the quasi-linear model in the Appendix). Let $t_{i}$ denote the proportion of good $i$ that is allocated to private consumption in the two-person household (of which half is consumed by each person) and $1-t_{i}$ the proportion consumed as a pure public good (of which each person consumes the full amount). Then, each person will consume $q_{i j}=t_{i} q_{i} / 2+\left(1-t_{i}\right) q_{i}$ which implies that $q_{i}=2 /\left(2-t_{i}\right) q_{i j}$ and hence that $r_{i}=2 /\left(2-t_{i}\right)$. In the appendix, more general formulations for semi-public goods are described which permit unequal consumption (following Lau, 1985). However, the simple equal consumption framework here is more useful for the introduction of modelling assumptions.

As an example, consider the running costs of a car on a given day. If the car travels $1 \mathrm{~km}$ taking (only) person 1 to a destination, $1 \mathrm{~km}$ for person 2 and $1 \mathrm{~km}$ to a destination for both people, then $t=2 / 3$ and $r=1.5$. That is, each person travels $2 \mathrm{~km}$, but the car must travel $3 \mathrm{~km}$. The running costs for the household of 2 people is thus 1.5 times the running costs associated with the consumption of a single person.

Goods that are essentially private but which involve a fixed wastage overhead can be conceptualised in the same way. If on, average, each individual consumes $950 \mathrm{ml}$ of milk per day and the last $100 \mathrm{ml}$ of household milk consumption is wasted, we can think of this 5 per cent wastage out of the 2 litre consumption in the two-person household as the public fraction, implying that the relative purchase requirement of the two person household is $2 /(2-0.95)=2000 / 1050=1.905$.

This example also illustrates one limitation of the modelling framework - it does not consider economies of scale of the production function type. That is, the same wastage efficiencies gained from the two person household should also be available to a single person household who drinks twice as much milk. The model could in principle be generalised to include such characteristics of production, but here we focus only on 
variation across household composition and the modelling assumptions made below should thus be considered as applying to average consumption levels.

Introducing assumptions about consumption sharing is easier the more detailed the commodity specification, but this makes the methodology less transparent. A compromise approach is to group commodities according to their relative purchase requirements, as is done in Table 1 . The table shows two representations of the relative purchase requirements of couple households. The first set of data columns shows the author's assumptions of the amount needed to be purchased by the couple household in order for each individual to have one unit of personal consumption (the $r_{i}$ parameters). Low, preferred and high values for these parameters are given. Values of 1 indicate pure public goods, 2, pure private. The relative shadow price facing the individuals in the couple household is half the $r_{i}$ value. The second set expresses these same relationships from the perspective of the quasi-linear model of purchase requirements, where the good is assumed to comprise two parts, one pure private and one pure public. The $t_{i}$ parameters show the fraction of the good that is private.

A few goods (clothing, tobacco, health insurance, transport fares) are assumed to be purely private. Most other goods are assumed to be either close to private or close to public (see also Figure 1 below). Goods that are assumed close to private include alcohol and personal food such as biscuits, fruit, processed meat, breakfast cereals, cakes, nonalcoholic drinks, dairy products (other than milk), spreads, tea, coffee, confectionary, tinned fish, etc. Even though each unit of food is only consumed by one person, these are assumed not to be fully private because wastage means that singles need to purchase more than half the amount of couples in order to have the same consumption. For these goods, the low, preferred and high relative requirements assumptions are set at 1.8, 1.9 and 2.0 respectively. Equivalently, we can think of these goods as having between zero and 11 per cent of a public component- which in this case can be interpreted as the fraction that is wastage in the couple household. 
Table 1 Commodity categories and relative purchase requirement assumptions

Expenditure Categories

Assumed degree of sharing

Relative purchase

required (r: $1=$ Fraction of good

pure public, $2=$ that is private

pure private $) \quad(\mathrm{t}=2(1-1 / \mathrm{r}))$

Low Pref. High Low Pref. High

\begin{tabular}{|c|c|c|c|c|c|c|c|}
\hline Housing & Repairs and maintenance, rent, land and water supply taxes & 1.00 & 1.15 & 1.30 & 0.00 & 0.26 & 0.46 \\
\hline Fuel & Electricity, gas etc (not transport fuels) & 1.20 & 1.30 & 1.40 & 0.33 & 0.46 & 0.57 \\
\hline Prepared food & $\begin{array}{l}\text { Foods that require preparation and/or are perishable such as flour, } \\
\text { rice, pasta, vegetables, bread, unprocessed meat and milk }\end{array}$ & 1.60 & 1.75 & 1.90 & 0.75 & 0.86 & 0.95 \\
\hline Eat out & Restaurants, take-away food & 1.90 & 1.95 & 2.00 & 0.95 & 0.97 & 1.00 \\
\hline Personal food & $\begin{array}{l}\text { Biscuits, fruit, processed meat, breakfast cereals, cakes, non-alcoholic } \\
\text { drinks, dairy products (other than milk), spreads, tea, coffee, } \\
\text { confectionary, tinned fish, etc. }\end{array}$ & 1.80 & 1.90 & 2.00 & 0.89 & 0.95 & 1.00 \\
\hline Alcohol & Alcohol & 1.80 & 1.90 & 2.00 & 0.89 & 0.95 & 1.00 \\
\hline Tobacco & Tobacco & 2.00 & 2.00 & 2.00 & 1.00 & 1.00 & 1.00 \\
\hline Clothing & Clothing & 2.00 & 2.00 & 2.00 & 1.00 & 1.00 & 1.00 \\
\hline $\begin{array}{l}\text { Shared } \\
\text { furnishings \& } \\
\text { equipment }\end{array}$ & $\begin{array}{l}\text { Lounge room, kitchen and garden furniture, art, major appliances and } \\
\text { household tools }\end{array}$ & 1.10 & 1.20 & 1.40 & 0.18 & 0.33 & 0.57 \\
\hline $\begin{array}{l}\text { Other } \\
\text { furnishings }\end{array}$ & Floor coverings, curtains, other furniture & 1.20 & 1.30 & 1.40 & 0.33 & 0.46 & 0.57 \\
\hline $\begin{array}{l}\text { Household } \\
\text { shared } \\
\text { operation }\end{array}$ & Gardening services, nails, screws etc. & 1.00 & 1.05 & 1.10 & 0.00 & 0.10 & 0.18 \\
\hline Communication & Telephone and post & 1.20 & 1.30 & 1.50 & 0.33 & 0.46 & 0.67 \\
\hline Cleaning & Soaps and detergents (not personal), wraps, gardening products etc & 1.20 & 1.30 & 1.50 & 0.33 & 0.46 & 0.67 \\
\hline Hygiene & Household paper (not stationery), toilet paper and tissues & 1.80 & 1.90 & 2.00 & 0.89 & 0.95 & 1.00 \\
\hline $\begin{array}{l}\text { Health } \\
\text { insurance }\end{array}$ & Health insurance & 2.00 & 2.00 & 2.00 & 1.00 & 1.00 & 1.00 \\
\hline Medical & Dental and medical fees and medications & 1.90 & 1.95 & 2.00 & 0.95 & 0.97 & 1.00 \\
\hline Transport fares & Air, bus, rail fares etc (excluding holiday fares). & 2.00 & 2.00 & 2.00 & 1.00 & 1.00 & 1.00 \\
\hline $\begin{array}{l}\text { Vehicle fixed } \\
\text { costs }\end{array}$ & Vehicle registration and insurance, purchase, accessories etc & 1.00 & $\mathbf{1 . 0 5}$ & 1.10 & 0.00 & $\mathbf{0 . 1 0}$ & 0.18 \\
\hline $\begin{array}{l}\text { Vehicle } \\
\text { running }\end{array}$ & Vehicle operating costs such as petrol, vehicle servicing etc & 1.20 & 1.30 & 1.40 & 0.33 & 0.46 & 0.57 \\
\hline $\begin{array}{l}\text { Shared } \\
\text { recreation }\end{array}$ & $\begin{array}{l}\text { Shared goods such as newspapers, televisions, stereos and associated } \\
\text { supplies; pets, general holiday expenditures }\end{array}$ & 1.00 & 1.20 & 1.40 & 0.00 & 0.33 & 0.57 \\
\hline $\begin{array}{l}\text { Personal } \\
\text { recreation }\end{array}$ & $\begin{array}{l}\text { Books, magazines, gambling, sports, admission charges, and holiday } \\
\text { travel. }\end{array}$ & 1.60 & 1.75 & 1.90 & 0.75 & 0.86 & 0.95 \\
\hline Personal care & Haircuts, toiletries and cosmetics etc & 1.80 & 1.90 & 2.00 & 0.89 & 0.95 & 1.00 \\
\hline $\begin{array}{l}\text { Gifts and } \\
\text { shared misc }\end{array}$ & Gifts, misc property payments, personal advertising, etc & 1.00 & 1.10 & 1.20 & 0.00 & 0.18 & 0.33 \\
\hline $\begin{array}{l}\text { Misc not } \\
\text { shared }\end{array}$ & $\begin{array}{l}\text { Child support/alimony payments, jewellery, and accessories, } \\
\text { education fees, professional association subscriptions, etc }\end{array}$ & 1.80 & 1.90 & 2.00 & 0.89 & 0.95 & 1.00 \\
\hline $\begin{array}{l}\text { Misc part } \\
\text { shared }\end{array}$ & $\begin{array}{l}\text { Miscellaneous commodities and services nec, stationary, fees and } \\
\text { fines, non-housing interest payments, etc }\end{array}$ & 1.20 & 1.50 & 1.80 & 0.33 & 0.67 & 0.89 \\
\hline
\end{tabular}


In general, it might be possible to gather this data in other ways, for example via in-depth studies of food wastage, studies of which types of journeys are undertaken singly or in company, or consultations with people in older households similar to the focus group consultations undertaken in budget standards studies. To take another example, household expenditure on fuel predominantly comprises water heating, home heating/cooling and cooking. The first of these is primarily used for bathing and has little joint consumption, while joint consumption is substantial for the others. Data collected by the utility industries on the relative importance of these different components in typical households could be used to provide more precise scale economy bounds than given here.

Returning to Table 1, other close-to-private goods include eating out (a negligible amount of meal sharing is assumed), prepared food (a larger wastage fraction than personal food), personal hygiene goods (mainly toilet paper and tissues, assumed not shared), medical fees (less per-person wastage of non-prescribed medications in couple households), personal care (some sharing of toiletries), and miscellaneous goods that are likely to be personally consumed.

On the other hand, housing is assumed to be close to fully public, with couples requiring not much more housing than singles. This assumption is based on social norms of housing consumption in Australia, which in turn derive from the limited liquidity of owner-occupied housing. It is assumed that housing is not perfectly public because it might be considered normal for members of a couple to have slightly more space to accommodate activities only undertaken by one member (e.g. a sewing room). The preferred estimate assumes that about one-quarter of the value of house is privately consumed and the remainder public (though the suggested bounds range from an assumption of fully public to $46 \%$ public).

Other goods which are closely linked to housing are assumed to have a similar degree of sharing (fuel, furniture, household operation, cleaning, shared recreation goods). Telephone and postal costs are assumed to be substantially shared because of overlaps between the social contacts of the couple. Vehicle costs are split into fixed costs (it is assumed that a couple will not need an extra vehicle) and running costs, where it is 
assumed that vehicles owned by couples need to go on 20 to 40 per cent more journeys to attain the same mobility as obtained by a single person.

The observed average budget shares in 2003-04 for singles and married couples over Age Pension age are shown in Table 2. Goods that have budget shares over 5 per cent are shown in bold to aid identification of the most important goods in the equivalence scale calculation. These are housing (mainly maintenance and taxes), food, medical expenses, vehicle costs, and recreation. Couples tend to spend a lower proportion of their total expenditure on goods such as housing which have a high degree of joint consumption. Some of the differences between singles and couples might also reflect the fact that singles are generally older. Variations across age are considered in Section 5 below.

At the preferred values of the relative purchase requirements for couples, the Laspeyres scale (based on the singles budget share) yields a value of 1.48 and the Paasche scale based on the expenditure patterns of couples a scale of 1.44. A much greater variation arises if we base conclusions on the low or the high assumptions for the commodityspecific scales. The Fisher scale (the average of Laspeyres and Paasche) ranges from 1.35 to 1.58 , with a preferred value of 1.46 . The pre-2009 relativity in the Australian Age Pension, of 1.64, is greater than all these estimates, implying that home-owning couples reliant solely on the Age Pension had a higher living standard than corresponding single people.

The bottom panel of the table also shows the Fisher scale calculated from the budget shares of singles in the middle income quintile group (of singles) and of corresponding middle-income couples. These scales are marginally higher than the scales calculated from the overall budget shares shown in the table (1.47 vs 1.46 for the preferred scale). The last line of the table also shows the impact of using the iterative approach described in Section 3 which ensures that the budget shares represent the consumption patterns of couples and singles at approximately the same welfare level. These are marginally higher again (1.48). Because these differences are so small, and because of the greater statistical precision of the overall budget shares, the simple scales based on the overall budget shares are used as the base estimates here. 
The final column of Table 2 shows a set of $r$ values chosen to ensure that the Fisher scale (based on the overall budget shares) will be equal to the pre-2009 pension relativity. ${ }^{8}$ Though this is not a unique scaling, this suggests that high relative purchase requirements for couples might be needed in order to justify the current pension relativity. For example, couples might be required to spend 1.38 times that of singles to attain the same per-person standard of housing consumption.

Undertaking the budget share calculation for the years 1988-89, 1993-94, 1998-99 and 2003-04 yields estimates for the Fisher preferred scale of 1.49, 1.48, 1.47 and 1.46 for the four years. This steady fall in relative needs has been driven by falls in the budget shares of home-eaten food and clothing, together with increases in the budget shares of vehicle fixed costs and housing. These trends have been partly offset by increases in eating out, medical, and personal recreation. Figure 1 plots these changes in budget shares against the degree of sharing for each commodity. There are few goods in the bottom-left of the figure, implying a general increase in the budget share among goods that have greater economies of sharing.

The reasons for these changes in expenditure patterns probably include income effects (e.g. the elderly are now richer and more likely to purchase vehicles), price effects (e.g. clothing is cheaper), and possibly also taste changes. But whatever the reasons, the trend is clearly towards increases in the relative needs of singles. Alternative assumptions about the degree of commodity sharing are not likely to change this conclusion, unless they are so large as to move more goods into the bottom-left corner of Figure 1. ${ }^{9}$

8 As noted above, $r_{i}=2 /\left(2-t_{i}\right)$ and so $t_{i}=2\left(1-1 / r_{i}\right)$, which is bounded between 0 and 1 . Let $L_{i}=\ln \left(t_{i} /\left(1-t_{i}\right)\right), L_{i}^{*}=a+L_{i}, t_{i}^{*}=1 /\left(1+\exp \left(-L_{i}^{*}\right)\right), r_{i}^{*}=2 /\left(2-t_{i}^{*}\right)$ and calculate the Fisher equivalence scale based upon $r_{i}^{*}$. Then adjust $a$ until the Fisher scale equals the current pension relativity of 1.64.

9 See Blundell and Lewbel (1991) and Banks and Johnson (1994) for more discussion of the implications of price changes for changes in consumer equivalence scales. 
Table 2 2003-04 budget shares and equivalence scales based on alternative relative need assumptions

\begin{tabular}{|c|c|c|c|c|c|c|}
\hline \multirow[b]{2}{*}{ Expenditure category } & \multicolumn{2}{|c|}{$\begin{array}{l}\text { Budget share } \\
(>5 \% \text { in bold })\end{array}$} & \multicolumn{3}{|c|}{$\begin{array}{l}\text { Relative needs for couples } \\
\text { (r) }\end{array}$} & \multirow{2}{*}{$\begin{array}{l}\text { Implied } \\
\text { Current }\end{array}$} \\
\hline & Singles & Couples & Low & Preferred & High & \\
\hline Housing & 0.182 & 0.089 & 1.00 & 1.15 & 1.30 & 1.38 \\
\hline Fuel & 0.042 & 0.034 & 1.20 & 1.30 & 1.40 & 1.60 \\
\hline Prepared food & 0.065 & 0.077 & 1.60 & 1.75 & 1.90 & 1.91 \\
\hline Eat out & 0.039 & 0.040 & 1.90 & 1.95 & 2.00 & 1.99 \\
\hline Personal food & 0.078 & 0.091 & 1.80 & 1.90 & 2.00 & 1.97 \\
\hline Alcohol & 0.018 & 0.025 & 1.80 & 1.90 & 2.00 & 1.97 \\
\hline Tobacco & 0.004 & 0.006 & 2.00 & 2.00 & 2.00 & 2.00 \\
\hline Clothing & 0.027 & 0.031 & 2.00 & 2.00 & 2.00 & 2.00 \\
\hline Shared furnishings \& equipment & 0.041 & 0.035 & 1.10 & 1.20 & 1.40 & 1.46 \\
\hline Other furnishings & 0.014 & 0.025 & 1.20 & 1.30 & 1.40 & 1.60 \\
\hline Household shared operation & 0.028 & 0.018 & 1.00 & 1.05 & 1.10 & 1.15 \\
\hline Communication & 0.037 & 0.029 & 1.20 & 1.30 & 1.50 & 1.60 \\
\hline Cleaning & 0.012 & 0.013 & 1.20 & 1.30 & 1.50 & 1.60 \\
\hline Hygiene & 0.003 & 0.004 & 1.80 & 1.90 & 2.00 & 1.97 \\
\hline Health insurance & 0.026 & 0.034 & 2.00 & 2.00 & 2.00 & 2.00 \\
\hline Medical & 0.069 & 0.048 & 1.90 & 1.95 & 2.00 & 1.99 \\
\hline Transport fares & 0.006 & 0.002 & 2.00 & 2.00 & 2.00 & 2.00 \\
\hline Vehicle fixed costs & 0.060 & 0.089 & 1.00 & 1.05 & 1.10 & 1.15 \\
\hline Vehicle running expenses & 0.050 & 0.060 & 1.20 & 1.30 & 1.40 & 1.60 \\
\hline Shared recreation & 0.050 & 0.066 & 1.00 & 1.20 & 1.40 & 1.46 \\
\hline Personal recreation & 0.059 & 0.094 & 1.60 & 1.75 & 1.90 & 1.91 \\
\hline Personal care & 0.021 & 0.022 & 1.80 & 1.90 & 2.00 & 1.97 \\
\hline Gifts and shared misc & 0.038 & 0.032 & 1.00 & 1.10 & 1.20 & 1.28 \\
\hline Misc not shared & 0.005 & 0.006 & 1.80 & 1.90 & 2.00 & 1.97 \\
\hline Misc part shared & 0.025 & 0.030 & 1.20 & 1.50 & 1.80 & 1.78 \\
\hline Sample size & 472 & 533 & & & & \\
\hline \multicolumn{2}{|c|}{ Upper bound equivalence scale (Laspeyres) } & & 1.38 & 1.48 & 1.60 & 1.65 \\
\hline \multicolumn{2}{|c|}{ Lower bound equivalence scale (Paasche) } & & 1.32 & 1.44 & 1.57 & 1.63 \\
\hline \multicolumn{2}{|c|}{ Geometric mean (Fisher ideal) } & & 1.35 & 1.46 & 1.58 & 1.64 \\
\hline \multicolumn{2}{|l|}{ (Jackknife standard error) } & & $(0.011)$ & $(0.010)$ & $(0.010)$ & \\
\hline \multicolumn{7}{|c|}{ Inverse (singles/couples) } \\
\hline \multicolumn{2}{|c|}{ Upper bound equivalence scale (Laspeyres) } & & 0.727 & 0.674 & 0.624 & 0.605 \\
\hline \multicolumn{2}{|c|}{ Lower bound equivalence scale (Paasche) } & & 0.757 & 0.694 & 0.639 & 0.614 \\
\hline \multicolumn{2}{|c|}{ Geometric mean (Fisher ideal) } & & 0.742 & 0.683 & 0.631 & 0.610 \\
\hline \multicolumn{7}{|l|}{ For middle income quintile groups } \\
\hline \multicolumn{2}{|l|}{ Geometric mean (Fisher ideal) } & & 1.35 & 1.47 & 1.59 & \\
\hline Geo mean at approx same welfare & & & 1.36 & 1.48 & 1.60 & \\
\hline
\end{tabular}

Source: ABS Household Expenditure Survey 2003-04, Confidentialised unit record file. Author's relative needs assumptions. 
Figure 1 Trend change in budget share 1988-89 to 2003-04 by assumed relative needs of couples

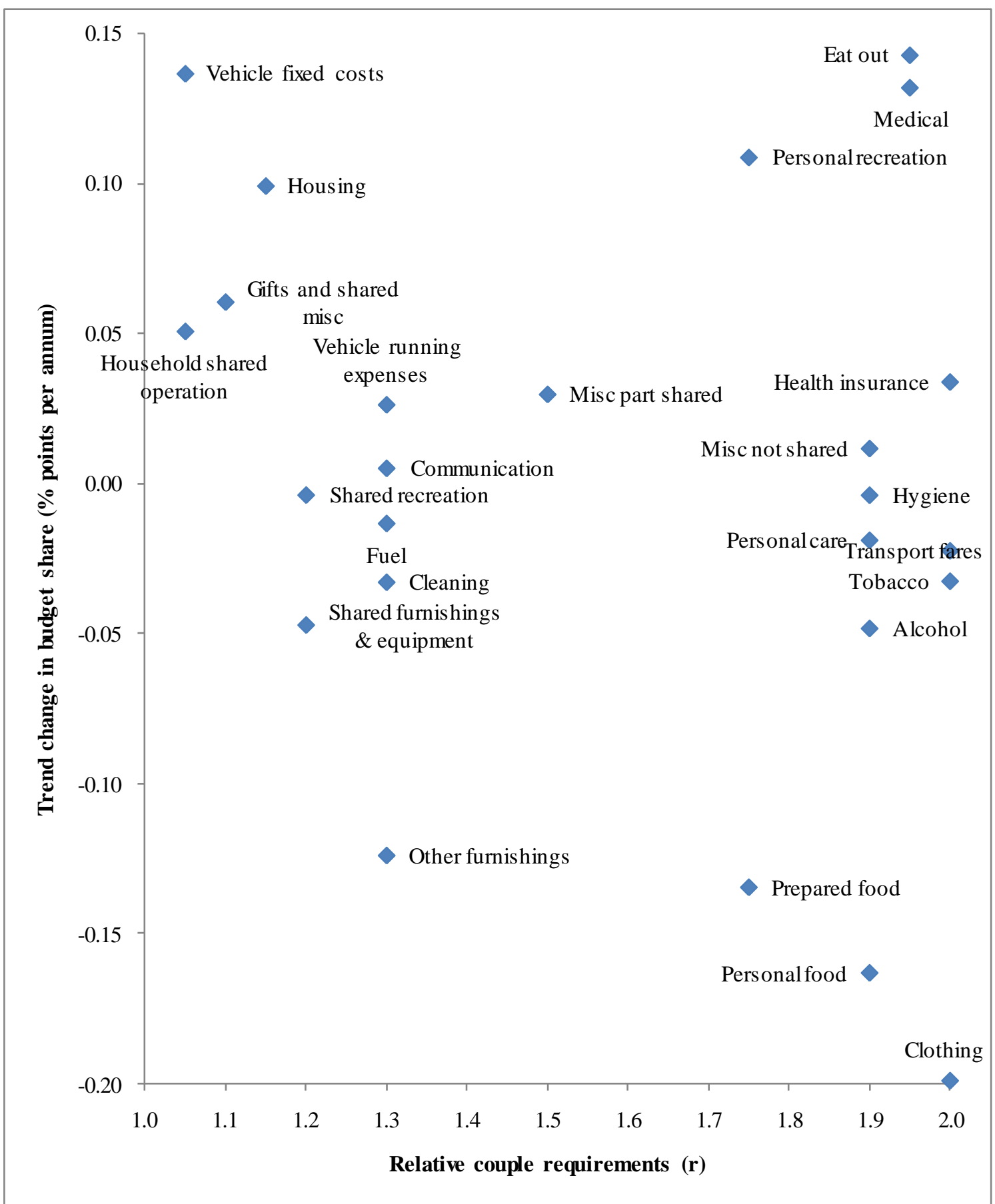

Notes: Trend change in budget share is estimated as a linear trend through the budget shares for each of the 4 years (average of couple and single trend). 


\section{Extensions}

\subsection{Cost variations with age and income}

The single elderly are on average older than those living in couples. Does this affect the calculations of the relative needs of singles and couples? The above calculations were repeated for young and old households. Young households are single or couple households where the male (if present) is aged 65-69 and the female (if present) is aged 62-69. In old households the members are aged 75 or higher. Old households tend to spend a larger fraction of their total expenditure on housing and medical care, and smaller fraction on vehicle fixed costs (e.g. purchases), personal recreation (e.g. travel) and eating out. ${ }^{10}$ However, there is no clear tendency for older households to shift their consumption towards goods that are either relatively public or private. The result is that the estimates of relative needs are very similar. For both the young and old groups, the preferred relative need Fisher scale is 1.47 , only slightly higher than the overall estimate above of 1.46 .

Similarly, the estimates in the previous section are for single and couple Australians of Age Pension age. Restricting the analysis to those actually receiving income support payments (the poorer $3 / 4$ of the population), the estimates are also slightly larger, with the Fisher relativities ranging from 1.36 to 1.59, with a preferred value of 1.47.

A more detailed investigation of budget allocation across income ${ }^{11}$ quintile groups does yield some apparent differences. Singles and couples are separately classified into quintile groups based on disposable income (eg the $20 \%$ of singles with the lowest income assigned to quintile group 1). The simple Fisher relativities based on the preferred scales are $1.44,1.48,1.47,1.49$ and 1.46 for the low to high income groups respectively. Alternatively, starting from the single quintile groups and using the interpolation procedure described in Section 3 to estimate the scales when couples are at

\footnotetext{
10 Tables showing these budget shares are available in Bradbury (2009).

11 Footnote 6 explains why income rather than expenditure grouping is used.
} 
approximately the same welfare level, yields estimates of $1.44,{ }^{12} 1.45,1.48,1.48$ and 1.46. These results suggest that couples at the top and bottom of the income distribution might need less than those in the middle of the distribution - but the differences are not large.

\subsection{Equivalence scales for private renters}

All the above calculations are based on the consumption patterns of home owners. Though this is by far the most common housing situation of the elderly in Australia, there are still substantial numbers of elderly who do not own their own homes. The 2003-04 HES, for example, reports that, of those people of age-pension age living in private households, 86 per cent owned their own home (some with mortgages), 5 per cent were paying rent to a government landlord, 7 per cent to other landlords, and 2 per cent were living in other tenure arrangements (including rent-free).

The Age Pension recognises the additional costs of renters by providing Rent Assistance to pension recipients renting in the private market. Singles are actually paid slightly more than couples in recognition of the strong economies of sharing associated with accommodation costs. For single and couple renters receiving the maximum rate of payment, the payment ratio for all payments combined is thus 1.53 (compared to 1.64 for non-renters).

For home owners, housing costs make up 9 and 18 per cent of the budget for couples and singles respectively, whereas for renters (from a non-government landlord), housing costs amount to 27 and 38 per cent on average. Since housing is very much shared, we would expect this difference in expenditure patterns to be associated with a lower estimate of couple relative needs, and this is indeed the case. For renters, the preferred Fisher scale is 1.40 (compared to 1.46 for owners). Using the high relative needs assumptions the Fisher scale is 1.53, which is equal to the actual pre 2009 pension relativity.

12 Interpolation is it not possible for the bottom quintile, and it is necessary to assume that the Paasche scale is constant within the whole of the bottom quintile of couples. 


\subsection{Unrelated two-person households}

What impact does sharing with a person other than one's spouse/partner have on relative expenditure needs? Among non-partnered people over age-pension age, about 22 per cent live with other people - 13 per cent with just one other person and 9 per cent with two or more (2003-04 HES). These multi-person households can take advantage of some aspects of household joint consumption, but not others typically available to couples (eg they are unlikely to share a bedroom). The model used here can be also used to consider the situation of two unrelated people sharing a household - even if there are insufficient people in the survey data to reliably calculate their budget shares. This is done by using the Laspeyres scale, which only requires information on the budget shares of single person households. This data, when combined with a revised set of sharing assumptions, can then be used to obtain relative need estimates. This is done in Bradbury (2009), where it is concluded that unrelated pairs would require 1.62 times the expenditure of singles (compared to 1.48 for the Laspeyres scale for couples). Of course, this estimate, like all those here, takes no account of the direct benefits of household composition - the autonomy of solitude or the joys of company.

\section{Conclusion}

Based on the modelling framework and assumptions outlined above, it is concluded that Australian single and couple home-owners reliant on Age Pension will have the same effective commodity consumption levels when the pension for couples is between 1.32 and 1.60 times the single pension (with a preferred value of 1.46). All these values are lower than the pre-2009 pension relativity of 1.64.

In 2009 a review of the Australian Age Pension system recommended increases to the single rate of Age Pension (Harmer, 2009). The research reported here was one source of evidence drawn upon by the Review. Subsequently, increases in the pension were announced, taking effect in September 2009, bringing the relativity between singles and couples down to around 1.5 - within the 'plausible bounds' considered here. These bounds are based a set of assumptions about upper and lower bounds for joint consumption together with household survey data on average budget shares. 
The methodology here can also be used in applications where there is very limited survey data. Among private renters (a small fraction of the Australian aged population), the required relativities are lower because housing comprises a larger share of the household budget. For this group the couple relativity ranges from 1.26 to 1.54 times the single rate, with a preferred value of $1.40 .{ }^{13}$ Similarly, the relativity for two person households who are not couples (eg siblings living together), can be estimated based on the consumption patterns of single adults combined with different sharing assumptions. All these estimates relate to the allocation and sharing of purchased commodities within the household. No account is made of preferences for different household types, home production, or the possible behavioural effects of income support policies.

13 The pre-2009 relativity of 1.53 for maximum rent assistance recipients falls at the edge of this range. 


\section{$7 \quad$ References}

Apps, Patricia and Ray Rees (1997), 'Collective Labor Supply and Household Production' Journal of Political Economy 105(1), February, 178-90.

Banks, James and Paul Johnson (1994), 'Equivalence scales and public policy', Fiscal Studies 15(1):1-23.

Barber, John; Gillian Moon and Sharon Doolan (1994), Question of Balance. A Discussion Paper Presenting Issues and Options Arising from the Strategic Review of the Pensions' Income and Assets Tests Department of Social Security, Canberra.

Barten, Anton P. (1964), 'Family Composition, Prices and Expenditure Patterns' in P. E. Hart, G. Mills and J. K Whitaker (eds) Econometric Analysis for National Economic Planning London, Butterworths.

Becker, Garry (1981), A Treatise on the Family Harvard University Press, Cambridge.

Bittman, Michael (1991), 'Home-Centred: A Trap for Women?' Women and Leisure: Towards 2000 Proceedings of Conference, July 11-12, Newcastle University.

Blackorby, Charles and Donaldson, David (1991) Adult-equivalence scales and the economic implementation of interpersonal comparisons of well-being Discussion paper No. 91-08. Vancouver: University of British Columbia, Department of Economics.

Blundell, Richard and Arthur Lewbel (1991), 'The information content of equivalence scales' Journal of Econometrics, 50, 49-68.

Bradbury, Bruce (1989), 'Family size equivalence scales and survey evaluations of income and well-being' Journal of Social Policy 18(3):383-408.

Bradbury, Bruce (2003), 'The welfare interpretation of consumer equivalence scales' International Journal of Social Economics 30(7):770-787.

Bradbury, Bruce (1997) Family Size and Relative Need PhD Thesis UNSW.

Bradbury, Bruce (2009), 'Modelling the relative needs of single and couple Age Pensioners' Paper presented to the XXIII conference of the European Society for Population Economics, June [https://espe.conferenceservices.net/resources/321/1533/pdf/ESPE2009_0047_paper.pdf]

Browning, Martin; François Bourguignon; Pierre-André Chiappori and Valérie Lechene (1994), 'Incomes and Outcomes: a Structural Model of Intra-Household Allocation' Journal of Political Economy 102(6):1067-.

Browning, Martin; Pierre-Andre Chiappori and Arthur Lewbel (2006), 'Estimating consumption economies of scale, adult equivalence scales and household bargaining power' University of Oxford, Department of Economics, Discussion Paper No 289, October.

Buhmann, Brigitte, Lee Rainwater, Guenther Schmaus and Timothy Smeeding (1988), 'Equivalence scales, well-being, inequality and poverty: sensitivity estimates across ten countries using the Luxembourg Income Study (LIS) Database' Review of Income and Wealth, 34(2), June, 115-42.

Chiappori, Pierre-André (1988), 'Rational Household Labor Supply' Econometrica 56(January):63-89.

Chiappori, Pierre-André (1992), 'Collective Labor Supply and Welfare' Journal of Political Economy 100(3):437-467.

Deaton, Angus, S. and Muellbauer, John (1980a) Economics and Consumer Behaviour Cambridge University Press, Cambridge. 
Engel, Ernst (1857), 'Die Productions und Consumtionsverhaltnisse des Konigsreichs Sachsen' Zietscrift des Statischen Bureaus des Koniglich Sachischen Ministeriums des Innern, vol 3.

Gorman, William (1976), 'Tricks with utility functions' in M. J. Artis and A. R. Nobay eds, Essays in Economic Analysis: Proceedings of the 1975 AUTE Conference, Sheffield. CUP, Cambridge.

Harmer, Jeff (2009), Pension Review Report Commonwealth of Australia, ISBN: 978-1921380-28-0.

Kapteyn, Arie and Wansbeek, Tom (1985) 'The individual welfare function, a review' Journal of Economic Psychology, 6, 333-63.

Lau, Lawrence J. (1985), 'The Technology of Joint Consumption' in George R. Feiwel (ed) Issues in Contemporary Microeconomics and Welfare Macmillan.

Lewbel, Arthur (1989), 'Household equivalence scales and welfare comparisons' Journal of Public Economics39, 377-91.

Muellbauer, John (1977) 'Testing the Barten model of household composition effects and the cost of children' The Economic Journal, 87, September, 460-487.

Nelson, Julie (1988), 'Household Economies of Scale in Consumption: Theory and Evidence’ Econometrica 56(6):1301-1314.

Nelson, Julie (1993), 'Household Equivalence Scales: Theory versus Policy?' Journal of Labor Economics 11(3).

Panzar, John C. and Robert D. Willig(1976), "Vindication of a "Common Mistake" in Welfare Economics' Journal of Political Economy, 84(6):1361-1363.

Patterson, Nigel and Tammy Wolffs (1995), 'The Demand for Flexible Payment Arrangements' Social Security Journal, December, 97-119.

Pollak, Robert A. and Terence J. Wales (1979), Welfare comparisons and equivalence scales' The American Economic Review, 69(2), 216-221.

Pollak, Robert A. and Terence J. Wales (1981), 'Demographic variables in demand analysis' Econometrica, 49(6), 1533-1551.

Rothbarth, Erwin (1943), 'Note on a Method of Determining Equivalent Income for Families of Different Composition' Appendix IV in War-Time Pattern of Saving and Expenditure by Charles Madge, University Press, Cambridge.

Samuelson, Paul (1956) 'Social Indifference Curves' The Quarterly Journal of Economics LXX(1):1-22.

Saunders, Peter, Jenny Chalmers, Marilyn McHugh, Colette Murray, Michael Bittman and Bruce Bradbury (1998) Development of Indicative Budget Standards for Australia Policy

Research Paper Number 74, Department of Social Security, Canberra.

Yates, Ian (2009), COTA News June-July, Vol 5, No 3. 


\section{Appendix: Extensions}

\subsection{A general model incorporating unequal sharing and preference diversity}

Starting from equation (1), we can consider a more general household purchase function which does not necessarily assume equal consumption within the household. Let $Q_{i}\left(q_{i 1}, q_{i 2}\right)$ represent the (two adult) household purchase requirement for commodity $q_{i}$. Lau (1985) proposed that such a purchase function should have the following properties: equal to individual consumption when only one person consumes the commodity; nondecreasing in its arguments; symmetric; homogenous of degree 1 (a simplifying assumption ruling out economies of scale of the production function type); and quasiconvex (for a given quantity of goods purchased by the household, the sum of personal consumption levels will increase or stay the same as the consumption levels are made more equal). These assumptions imply that the quantity purchased by the household is at least as great as the amount consumed by every individual, that the sum of services received by all individuals is always greater than or equal to the quantity purchased, that $Q_{i}\left(q_{i 1}, q_{i 2}\right)$ is convex, and that $\frac{\partial Q_{i}}{\partial q_{i j}} \leq 1$ (see also Bradbury, 1997).

Denoting $\frac{\partial Q_{i}}{\partial q_{i j}}$ by $s_{i j}\left(q_{i 1}, q_{i 2}\right)$ or just $s_{i j}$ for notational convenience, it is straightforward to show that in the first-order conditions for the household maximisation problem, the effective (or shadow) price of commodity $i$ for person $j$ in the household is now $p_{i} s_{i j}$. This shadow price must always be less than, or equal to, the market price (because $\left.\frac{\partial Q_{i}}{\partial q_{i j}} \leq 1\right)$ and the shadow price must be non-increasing in the consumption of other household members (from convexity). Using Euler's theorem (and assuming differentiability), the homogeneity property allows the budget constraint to be written in terms of these shadow prices as

$$
y=\sum_{j}\left(\sum_{i} q_{i j} p_{i} s_{i j}\right)=y_{1}+y_{2}
$$

This provides a natural way to describe the allocation of household income amongst household members. Some simple examples of household purchase functions include 
- Private

$$
Q_{i}=q_{i 1}+q_{i 2}
$$

- Public

$$
Q_{i}=\max \left(q_{i 1}, q_{i 1}\right)
$$

- Quasi-linear

$$
Q_{i}=\max \left\{\frac{q_{i 1}+q_{i 2}}{2-t_{i}}, \max \left(q_{i 1}, q_{i 1}\right)\right\}
$$

- Iso-elastic

$$
Q_{i}= \begin{cases}\left(q_{i 2}^{1 / e_{i}}+q_{i 2}^{1 / c_{i}}\right)^{e_{i}} & 0<e_{i} \leq 1 \\ \max \left(q_{i 1}, q_{i 1}\right) & e_{i}=0\end{cases}
$$

The first formulation is the conventional private good assumption. The second describes the situation where the good is 'public' within the household, with consumption by one member not detracting from the consumption of another. The last two expressions are different ways of describing goods that are partly shared within the household. When the scale parameters $t$ or $e$ equal 1 , the good is private, and the household demand is simply the sum of the individual demands, whilst when $t$ or $e$ equal 0 , the good is pure public. These functions are illustrated in Figure 2.

The quasi-linear purchase function implies that a fixed fraction $\left(1-t_{i}\right)$ of the household purchase of a commodity is allocated to public consumption within the household, with the remainder allocated among individuals for private consumption. If personal consumption levels are sufficiently similar so that consumption is located strictly between points $\mathrm{A}$ or $\mathrm{B}$ in Figure 2 then the purchase function for commodity $i$ is simply $Q_{i}=\frac{q_{i 1}+q_{i 2}}{2-t_{i}}$ and the shadow price for person $j$ is independent of the consumption levels of other household members. The assumption that consumption occurs strictly between $\mathrm{A}$ and $\mathrm{B}$ is the more likely to be unrealistic the more public is the good (i.e. in Figure 2, the diagonal portion of the budget constraint shrinks as the good becomes more public). 
Figure 2 Household consumption possibility frontiers for a single commodity in a 2-person household

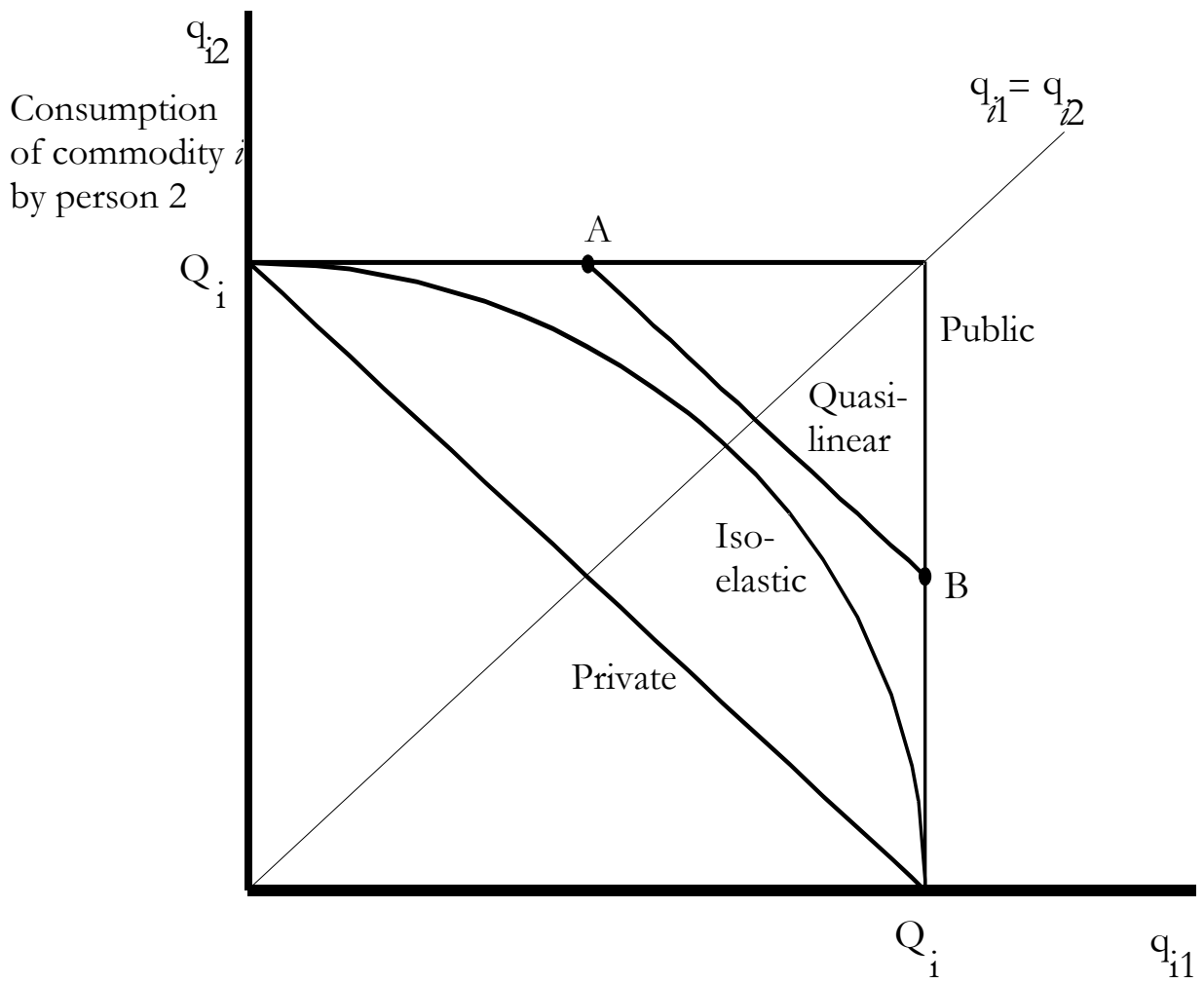

Consumption of commodity $i$ by person 1

Note: The figure shows the feasible combinations of consumption of commodity $i$ by person 1 and 2 when the household purchases a quantity qi.

The separable nature of the household welfare function in (1) means that household consumption decisions can be viewed in two stages. At the upper level, the allocation of household income to each member is decided. Consumption is then allocated to each individual to maximise their individual welfare function given their available income. The optimal solution at the lower level will be found when individuals (or the household decision-maker acting on their behalf) are maximising ${ }^{14}$

14 Since the shadow price inflator, $s_{i j}$, is a function of the consumption of commodity $i$ by all household members (unless the purchase function is quasi-linear), this relationship only applies when the shadow 


$$
\begin{aligned}
& U_{j}\left(q_{1 j}, q_{2 j}\right) \\
& \text { subject to } \sum_{i} q_{i j} p_{i} s_{i j} \leq y_{j}
\end{aligned}
$$

Denoting the share of household income allocated to the consumption of person $j$ as $\Theta_{j}(y, p)$, the budget constraint in (3) can be written as $\sum_{i} q_{i j} p_{i} s_{i j} \leq y \Theta_{j}(y, p)$. (The income share is, in general, a function of prices and household income). The household income required for person $j$ to reach welfare level $u_{j}$ is then

$$
c_{j}\left(u_{j}, p_{j}^{*}\right) / \Theta_{j}(y, p)
$$

where $c_{j}\left(u_{j}, p_{j}{ }^{*}\right)$ is the level of personal income which would enable person $j$ to reach welfare level $u_{j}$ when they face a vector of shadow prices $p_{j}^{*}$ (with elements $p_{i} s_{i j}$ ).

The consumer equivalence scale for individual $j$ is defined as the household income required to reach a standard of living $u_{j}$ when living with other people, divided by the income required to reach the same living standard when living alone. Since shadow prices are equal to market prices when living alone, this is thus given by

$$
m_{j}=c_{j}\left(u_{j}, p_{j}^{*}\right) /\left(\Theta_{j}(y, p) c_{j}\left(u_{j}, p_{j}\right)\right)
$$

where $c_{j}\left(u_{j}, p_{j}\right)$ is the cost of reaching welfare level $u_{j}$ when living alone and facing market prices. As discussed in the text, the equivalence scale will thus be decreasing in the share of income received by person $j, \Theta_{j}(y, p)$.

\subsection{The Gorman model}

If it is assumed that the household consists of identical individuals with equal sharing between them, then the model above simplifies to the Barten equivalence scale model with each commodity having a single scaling parameter indicating the degree of joint

prices are evaluated at the optimal household consumption vector. See Deaton and Muellbauer (1980a, pp 247-8) for a discussion of this approach to linearisation of the budget constraint. 
consumption. This is the model used in the main part of this paper. While maintaining the equal sharing and symmetry assumptions, it is also possible to generalise the consumption technology so that it can describe the characteristics of a model first described by Gorman (1976) (see also Pollak and Wales, 1981).

In the Barten model, household purchases of good $i$ are a scaled quantity of individual consumption $Q_{i}=r_{i} q_{i}$ (where $q_{i}$ denotes the consumption level of both person 1 and 2 and $Q_{i}$ the household purchase requirement). The budget constraint is then $\sum_{\mathrm{i}}\left(p_{i} r_{i} / 2\right) q_{i j} \leq y / 2$ with consumption allocated as if each individual were receiving half the household income and was facing prices that are $r_{i} / 2$ times market prices.

The consumer equivalence model of Gorman can be modelled by generalising this to $Q_{i}=a_{i}+b_{i} q_{i}$. In this case, the household budget constraint becomes

$\sum_{\mathrm{i}} p_{i} Q_{i} \leq y \quad$ or $\quad \sum_{\mathrm{i}} p_{i} \frac{b_{i}}{2} q_{i} \leq\left(y-\sum_{i} p_{i} a_{i}\right) / 2$

That is, some income is allocated to the fixed costs of the larger household, and then the remainder is allocated half to each person and expenditure chosen as if they faced prices $b_{i} / 2$ times market prices. Having fixed costs associated with household composition does not seem particularly plausible. However, this can be given a more meaningful interpretation if we write this as

$\sum_{\mathrm{i}} p_{i} \frac{r_{i}\left(q_{i}\right)}{2} q_{i} \leq y / 2 \quad$ with $\quad r_{i}\left(q_{i}\right)=b_{i}+a_{i} / q_{i}$

to indicate that the scaling parameter $r_{i}$ now varies with the quantity of the commodity purchased. If we wish to maintain the assumption that the relative needs of the larger household are between one and two times that of the smaller, then this implies that $a_{i}$ and $b_{i}$ must satisfy $1 \leq b_{i}+a_{i} / q_{i} \leq 2$ for the range of $q_{i}$ that we wish to model.

Though this is not done in this paper, such a modelling framework might be considered a suitable way to model the congestion issues associated with lumpy goods such as 
private vehicles. For a couple who do not travel much, a single vehicle might almost always be available when one of them needs to use it. In this case, expenditure on vehicle purchase and fixed costs might be considered to be close to a public good. On the other hand, if the couple travel a lot, then they might often have simultaneous needs to travel to different locations, and so they might need to purchase a second vehicle in order to obtain the transport consumption of a single person. In this case, $r_{i}\left(q_{i}\right)$ increases with $q_{i}$, implying $a_{i}<0$. Note that this is different from the usual Gorman model interpretation of the $a_{i}$ being the fixed (non-negative) costs of having a larger household. 